\title{
EFEK ZEOLIT UNTUK PRODUKSI TAR DAN CHAR PADA PIROLISIS ROTARY KILN
}

\author{
Widya Wijayanti \\ Tenaga Pengajar (Dosen) \\ Universitas Brawijaya \\ Jurusan Teknik Mesin \\ Email: widya_dinata@ub.ac.id
}

This study aims to investigate the effect of zeolite as a catalyst to enlarge biomass decomposition in the pyrolysis process. It absorbs a high water content in the biomass, besides it makes the easier breaking of biomass molecules to maximize the biomass decomposition into the expected pyrolysis products; tar and char. In addition, to decompose the biomass molecules, the zeolite also stimulates the rate of heat transfer due to its ability to hold and release the heat. If the previous research pyrolysis was conducted in a fixed bed reactor, in this study, it will be carried out rotary kiln as a pyrolysis furnace. If the fixed bed reactor the heat transfer was dominated by conduction, the heat transfer in the rotary kiln is more controlled by the convection and radiation transfer due to stirring and turning of biomass by the kiln. In the study, the biomass used was mahogany with an initial weight of 150 grams. The rotary kiln rotated at $10 \mathrm{rpm}$ and the heating rate during the pyrolysis process was around $0.1483^{\circ} \mathrm{C} / \mathrm{s}$. The pyrolysis temperatures used were varied as $250^{\circ} \mathrm{C}, 350^{\circ} \mathrm{C}, 450^{\circ} \mathrm{C}$. Meanwhile, the percentage of zeolites used from $0 \%$ to $60 \%$ with a mesh size of 80 . The results showed that zeolites were able to increase tar production and maximize the reduction of char as an effect of the Bronsted-Lowry and Lewis reaction in the process of catalytic cracking. The maximum production of tar and char production was also supported by the process of convection and radiation from the rotary kiln wall increasing the rate of heat transfer to decompose the biomass.

Keywords : Zeolit, Tar, Char, Pirolisis, Rotary Kiln.

\section{PENDAHULUAN}

Pembakaran langsung untuk bahan bakar padat seperti biomassa memiliki kelemahan, yaitu menimbulkan polusi udara berupa partikulat padat dan meningkatkan gas efek rumah kaca. Selain itu, dari sudut pandang exergy, hasil pembakaran langsung biomasa mempunyai temperatur pembakaran yang rendah akibat rendahnya nilai kalor biomassa tersebut. Berdasarkan kondisi tersebut, maka biomasa dapat ditingkatkan nilai kalornya melalui proses konversi energi dengan metode pirolisis. Pirolisis merupakan teknologi konversi dalam pembentukan energi terbarukan untuk menggantikan energi fosil. Dari penelitian sebelumnya, biomassa dengan proses pirolisis ini menghasilkan bahan bakar berupa bahan bakar padat (arang/char), bahan bakar cair (tar), dan bahan bakar gas $\left(\mathrm{CH}_{4}\right.$ dan $\left.\mathrm{H}_{2}\right)$.

Upaya peningkatan produk pirolisis terus dilakukan untuk menghasilkan bahan bakar dengan kualitas dan kuantitas maksimal. Salah satu cara yang dapat dilakukan untuk meningkatkan hasil produk pirolisis yang berupa tar (liquid) dan char (solid) adalah dengan pirolisis katalitik atau pirolisis dengan menggunakan katalis. Salah satu katalis yang dapat digunakan dalam proses mempercepat dekomposisi biomassa adalah zeolit. Katalis zeolit dalam proses pirolisis berfungsi untuk mempercepat laju reaksi dekomposisi atau penguraian rantai panjang hidrokarbon yang terdapat pada biomassa sehingga lebih cepat tebentuk rantai hidrokarbon pendek. Zeolit juga memiliki ukuran pori-pori besar sehingga zeolit memiliki selektifitas yang baik terhadap senyawa lain. Zeolit dipilih juga karena tersedia melimpah di alam dan mudah didapatkan. Indonesia sendiri merupakan salah satu negara yang memiliki zeolit yang melimpah [1]. Oleh karenanya, penggunaannya sebagai katalis dapat menurunkan biaya produksi [2]. 
Selain itu, untuk meningkatkan hasil tar dan char yang terbentuk semakin banyak dan berkualitas baik, maka dilakukan dengan penggunaan piroliser rotary kiln. Pada proses ini terjadi perpindahan panas lebih cepat antar partikel serbuk kayu mahoni karena partikel satu dengan yang lainnya saling bertubrukan akibat putaran tungku dan adanya sudu-sudu. Hal ini bertujuan agar terjadi pemerataan panas pada biomassa sehingga biomassa lebih cepat terdekomposisi saat proses pirolisis berlangsung. Pirolisis rotary kiln merupakan pengembangan tungku dimana tungku tersebut dapat berputar dan memiliki sudu-sudu sehingga biomassa dapat berpindah dari ujung ke ujung yang lain dengan kecepatan tertentu sesuai dengan putaran tungku ketika waktu pirolisis berlangsung.

DC Kumara [3] pernah melakukan penelitian pirolisis serbuk kayu dengan katalisator zeolit menggunakan fix bed. Dalam penelitian tersebut didapatkan bahwa semakin besar prosentase zeolit, maka semakin besar pula tar hasil pirolisis. Jumlah cairan hasil pirolisis pada sampel dengan katalis serbuk dalam reaktor lebih banyak dibanding pada sampel tanpa katalis. Selain itu F. Majedi [4] juga meneliti efek laju pemanasan pada produk-produk pirolisis dengan menggunakan fix bed. Hasil dari penelitian menunjukkan bahwa semakin besar temperatur pemanasan, maka massa dan volume tar yang dihasilkan juga semakin meningkat. Kebalikannay, dengan pemanasan yang semakin tinggi, maka reduksi char akan semakin meningkat juga.

Di dalam penelitian kali ini, proses pirolisis katalitik dilakukan pada rotary kiln agar pemerataan panas pada biomassa dapat tersebar merata. Penelitian ini bertujuan untuk melihat pengaruh katalis untuk peningkatan dekomposisi biomasa pada proses pirolisis. Adapun katalis yang digunakan pada penelitian ini adalah katalis zeolit yang mempunyai kemampuan penyerapan air tinggi, sehingga dapat memaksimalkan penguraian biomasa menjadi produk pirolisis yang diharapkan; tar dan char. Selain kemampuan dekomposisi biomasa yang meningkat akibat peran zeolit, peningkatan dekomposisi juga dilakukan melalui proses perpindahan panasnya yang sangat mempengaruhi penguraian senyawa-senyawa biomasanya. Oleh karena itu, apabila penelitian sebelumnya [3-9] proses pirolisis dilakukan pada fixed bed reactor, maka penelitian ini menggunakan rotary kiln sebagai furnace pirolisis. Bila fixed bed reactor didominasi oleh perpindahan panas secara konduksi, maka rotary kiln lebih banyak dikendalikan oleh perpindahan konveksi dan radiasi akibat pengadukan dan pemutaran biomassa oleh rotary kiln.

\section{METODE DAN BAHAN}

Pirolisis pada penelitian kali ini menggunakan jenis biomasa kayu mahoni dengan berat awal sebesar 150 gram. Putaran rotary kiln sebesar $10 \mathrm{rpm}$ dan laju pemanasan saat proses pirolisis sebesar $0,1483{ }^{\circ} \mathrm{C} / \mathrm{detik}$. Sedangkan temperatur pirolisis yang digunakan divariasikan sebesar temperatur proses pirolisis yang dipergunakan yaitu $250^{\circ} \mathrm{C}, 350^{\circ} \mathrm{C}, 450^{\circ} \mathrm{C}$. Temperatur yang digunakan cukup rendah, karena selain dilihat efek dekomposisi termal untuk pemecahan biomasa, juga akan dilihat efek perpindahan panas dari rotary kiln. Sedangkan luaran yang akan diamati untuk melihat efektifitas zeolit dan rotary kiln adalah produksi pirolisis yaitu tar dan charnya. Adapun prosentase penambahan zeolit yang digunakan pada penelitin ini sebesar 0\% hingga 60\% dengan ukuran mesh 80.

Pengujian dilakukan pada rotary kiln dengan skema alat yang dapat dilihat pada Gambar 1 .

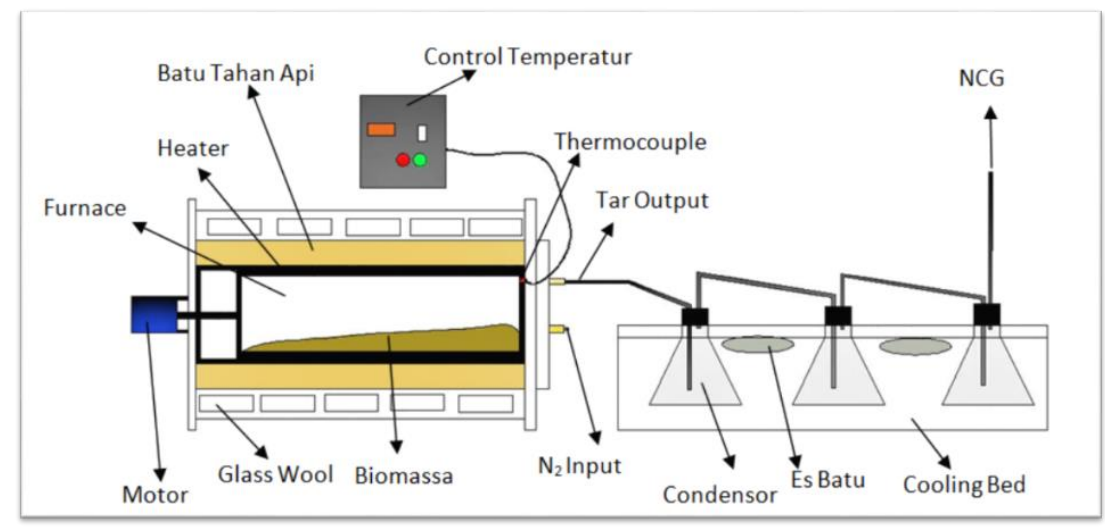

Gambar 1: Skema penelitian pirolisis rotary kiln

Sebelum dilakukan proses pirolisis, masing-masing komponen serbuk kayu mahoni dan zeolit ditimbang dengan massa total sebesar 150 gram. Masing-masing spesimen, divariasikan masa zaolite sebesar $15-60 \%$ dari masa total. Setelah itu spesimen campuran biomasa dan zeolit dimasukkan ke dalam tungku 
pirolisier. Selanjutnya, piroliser ditutup dan tungku dialiri gas $\mathrm{N}_{2}$ lewat katup $\mathrm{N}_{2}$ input dengan laju 3 1/menit. N2 dialirkan ke dalam piroliser agar gas $\mathrm{O}_{2}$ yang berada dalam tungku keluar untuk menghindari terjadinya pembakaran. Setelah itu heater dinyalakan dan temperatur diatur, masing-masing sesuai dengan variasi temperatur $250^{\circ} \mathrm{C}, 350^{\circ} \mathrm{C}, 450^{\circ} \mathrm{C}$. Pada penelitian ini, proses pirolisis berlangsung selama $2 \mathrm{jam}$.

Setelah proses pirolisis selesai, hasil yang didapat adalah produk solid(char) dan tar. Selanjutnya, produk-produk tersebut diukur volumenya menggunakan gelas ukur. Selain diukur volumenya, massa char dan tar juga diukur dengan menggunakan timbangan elektrik. Setelah didapatkan volume dan massa solid, maka volume dan massa solid tersebut dikurangi dengan volume dan massa zeolit sebelum dilakukan pirolisis dan didapatkan volume dan massa char produk pirolisis. Langkah tersebut dilakukan pada semua variasi.

\section{HASIL DAN DISKUSI}

\subsection{Profil Temperatur pada Rotary Kiln}

Untuk mengukur bersarnya panas yang diberikan ke biomasa, maka bersanya laju pemanasan perlu diketahui. Grafik hubungan antara lamanya waktu pemanasan pada temperatur piroliser dan dinding piroliser dapat dilihat pada Gambar 2. Pada grafik terlihat bahwa semakin lama waktu pemanasan (proses pirolisis) maka temperatur dalam tabung dan temperatur dinding tungku juga akan cenderung semakin naik. Dalam proses pengambilan data, data diambil setiap 10 menit sekali selama 120 menit atau 2 jam. Pada temperatur $250^{\circ} \mathrm{C}$ di menit ke- 0 , temperatur ambient adalah $25^{\circ} \mathrm{C}$, sedangkan pada menit ke- 10 kenaikan temperatur dalam tabung sebesar $89^{\circ} \mathrm{C}$ dan temperatur dindingnva adalah $104^{\circ} \mathrm{C}$.

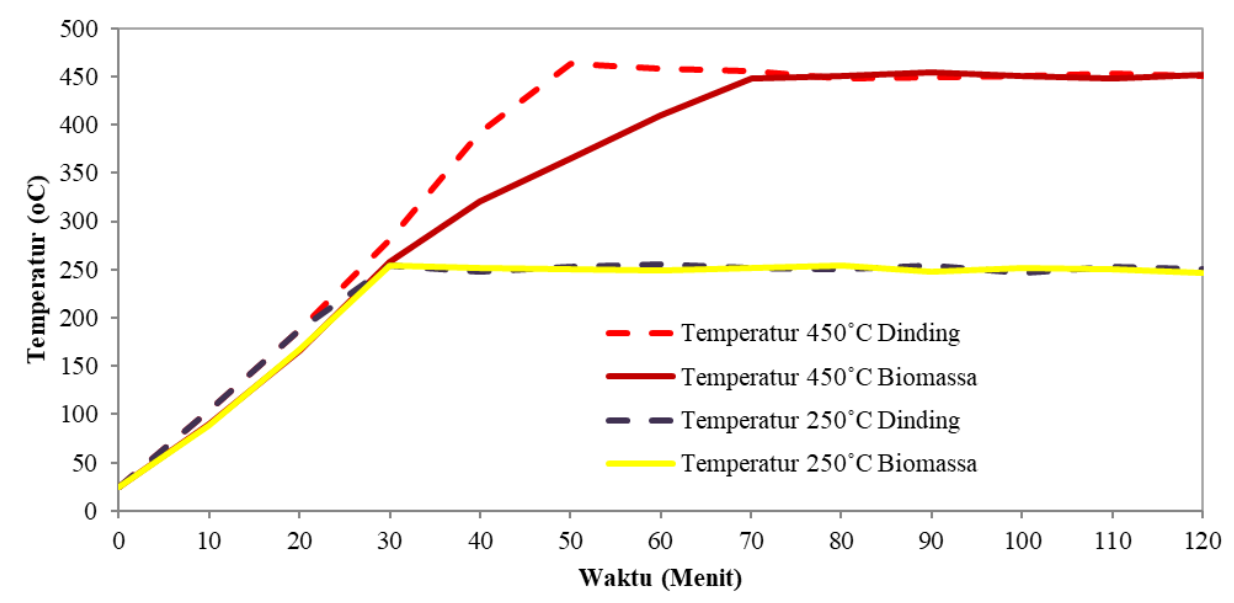

Gambar 2 : Grafik hubungan waktu terhadap temperatur dalam tungku dan dinding tungku

Pada menit ke-30, temperatur dinding tungku mencapai temperatur $254^{\circ} \mathrm{C}$. Setelah itu, temperatur dinding cenderung konstan pada $250^{\circ} \mathrm{C}$, sedangkan temperatur di dalam tabung juga mencapai temperatur $254^{\circ} \mathrm{C}$. Setelah itu, temperatur mencapai suhu equilibrium, terjadi kesamaan temperatur dalam tabung dan temperatur pada dinding tabung yaitu sebesar $250^{\circ} \mathrm{C}$. Kesesuaian tersebut terus terjadi hingga proses pirolisis selesai. Dari grafik tersebut dapat diprediksi bahwa pemanasan di dalam piroliser atau panas yang terjadi pada biomasa lebih kecil dibanding dinding piroliser, karena biomasa menyerap panas yang diberikan oleh dinding heater. Hal ini terjadi karena reaksi penyerapan panas oleh biomasa yang terjadi secara endotermik dibutuhkan untuk mendekomposisi biomasa, hingga pada kondisi equilibrium.

Begitu pula yang terjadi pada temperatur pirolisis $450^{\circ} \mathrm{C}$. Pada menit ke-10, kenaikan temperatur dalam tabung sebesar $90^{\circ} \mathrm{C}$ sedangkan temperatur dindingnya sebesar $104^{\circ} \mathrm{C}$. Pada menit ke-60, temperatur dinding tungku mencapai temperatur $458^{\circ} \mathrm{C}$ setelah itu temperatur dinding cenderung konstan $450^{\circ} \mathrm{C}$. Sedangkan dalam tabung mencapai temperatur $450^{\circ} \mathrm{C}$ pada menit ke-80, dan setelah itu terjadi kondisi eqilibrium. Kondisi equilibrium ini terus terjadi hingga proses pirolisis selesai.

\subsection{Pengaruh Prosentase Zeolit terhadap Volume Char pada Temperatur $250^{\circ} \mathrm{C}$ dan $450^{\circ} \mathrm{C}$}

Dari penelitan ini didapatkan volume produk akhir char pada $\mathrm{T}=250^{\circ} \mathrm{C}$ dan $\mathrm{T}=450^{\circ} \mathrm{C}$ dan pada berbagai variasi prosentase zeolit mulai $0 \%$ hingga $60 \%$. 


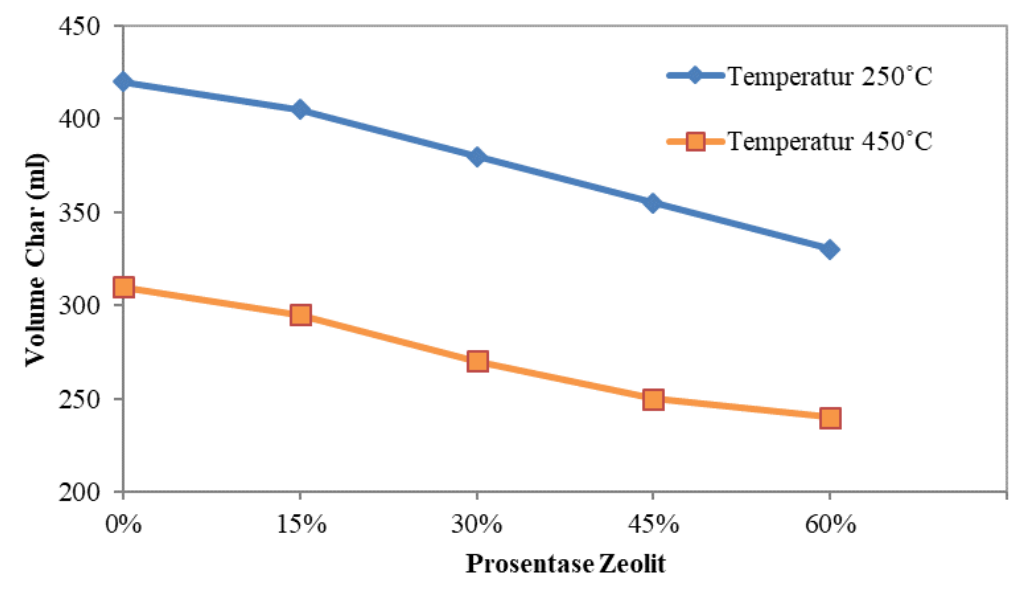

Gambar 3 : Grafik hubungan antara prosentase zeolit dan volume char

Pada gambar 3, ditunjukkan bahwa semakin besar prosentase zeolit yang digunakan saat proses pirolisis, maka semakin kecil volume akhir produk char yang dihasilkan. Hal ini disebabkan dengan semakin besarnya prosentase zeolit yang menyebabkan semakin banyak biomassa yang terdekomposisi. Akibatnya, biomassa banyak kehilangan volumenya. Saat pirolisis berlangsung, panas dari heater akan ditransfer ke zeolit, sehingga zeolit menjadi media perambatan termal dari bed rotary kiln menuju biomassa. Saat rotary kiln diputar, zeolit yang telah panas tersebut akan saling bersinggungan dengan, sehingga biomassa menjadi lebih panas. Hal ini sangat berbeda bila dibandingkan bila pirolisis terjadi tanpa adanya zeolit [3]. Volume akhir yang dihasilkan akan lebih besar dibandingkan dengan tanpa menggunakan zeolit. Dari penelitian ini didapatkan dengan semakin banyak prosentase penambahan zeolit yang digunakan, maka pemerataan panas dari tungku bed rotary kiln menuju biomassa semakin merata. Akibatnya, semakin banyak biomassa yang akan terdekomposisi menjadi gas, yang otomatis menyebabkan berkurangnya volume biomassa. Zeolit berfungsi sebagai perambat panas dari dinding rotary kiln ke biomassa karena kandungan alumina yang dimiliki oleh zeolit. Hal tersebut telah diteliti oleh Greenstein, A.M., et al [10] yang menyebutkan bahwa zeolit dapat sebagai konduktivitas termal sehingga mampu menjadi perambat panas. Mekanisme pemecahan rantai hidrokarbon pada proses catalytic cracking melibatkan reaksi Bronsted-Lowry dan Lewis pada proses pemecahan oleh katalis zeolit [11].

Dalam penelitian ini, temperatur pirolisis juga mempengaruhi penurunan volume produk char. Dari gambar 3 terlihat bahwa pirolisis pada $\mathrm{T}=450^{\circ} \mathrm{C}$ mengalami banyak kehilangan produk volume char dibandingkan pada $\mathrm{T}=250^{\circ} \mathrm{C}$. Semakin besar temperatur yag diberikan, maka energi untuk memecah ikatan biomasa akan semakin kuat. Oleh karena itu, semakin tinggi temperatur yang digunakan saat pirolisis, maka biomassa akan lebih banyak terdekomposisi baik dengan katalis maupun tanpa katalis. Dari penelitian ini, penurunan terbesar volume char terjadi pada saat pemberian temperatur $450^{\circ} \mathrm{C}$ dengan prosentase zeolit $60 \%$ yaitu sebesar $240 \mathrm{ml}$ sedangkan pada temperatur tersebut yang proses pirolisis tanpa katalis sebesar $310 \mathrm{ml}$. Pada suhu $250^{\circ} \mathrm{C}$, penurunan volume biomassa terbesar adalah ketika prosentase zeolit sebesar $60 \%$ yaitu sebesar $330 \mathrm{ml}$ sedangkan yang tanpa katalis volume biomassa produk char yang terbentuk sebesar $420 \mathrm{ml}$.

Dengan komponen serbuk kayu mahoni yang terdekomposisi dan asumsi kerapatan massanya konstan, maka dapat disimpulkan bahwa semakin besar prosentase zeolit dan temperatur yang digunakan, maka volume char yang terbentuk juga semakin kecil.

\subsection{Pengaruh Prosentase Zeolit terhadap Massa Char pada Temperatur $250^{\circ} \mathrm{C}$ Dan $450^{\circ} \mathrm{C}$}

Gambar 4 menunjukkan hubungan grafik antara prosentase zeolit terhadap massa char. Dari gambar tersebut terlihat bahwa semakin besar prosentase zeolit maka kecerendungan massa char semakin rendah. Hal ini sebanding dengan penurunan yang terjadi pada volume produk. Penurunan massa char terbesar pada prosentase zeolit $60 \%$ dengan $\mathrm{T}=450^{\circ} \mathrm{C}$. Dari gambar tersebut terlihat bahwa pada temperatur $450^{\circ} \mathrm{C}$ dengan prosentase zeolit $60 \%$ massa charnya adalah sebesar 24,2 gram sedangkan tanpa katalis zeolit massa charnya adalah sebesar 36,69 gram dan pada $\mathrm{T}=250^{\circ} \mathrm{C}$ dengan prosentase zeolit $60 \%$, massa charnya adalah sebesar 45,62 gram. Adapun massa char tanpa katalis zeolit adalah sebesar 54,16 gram. 


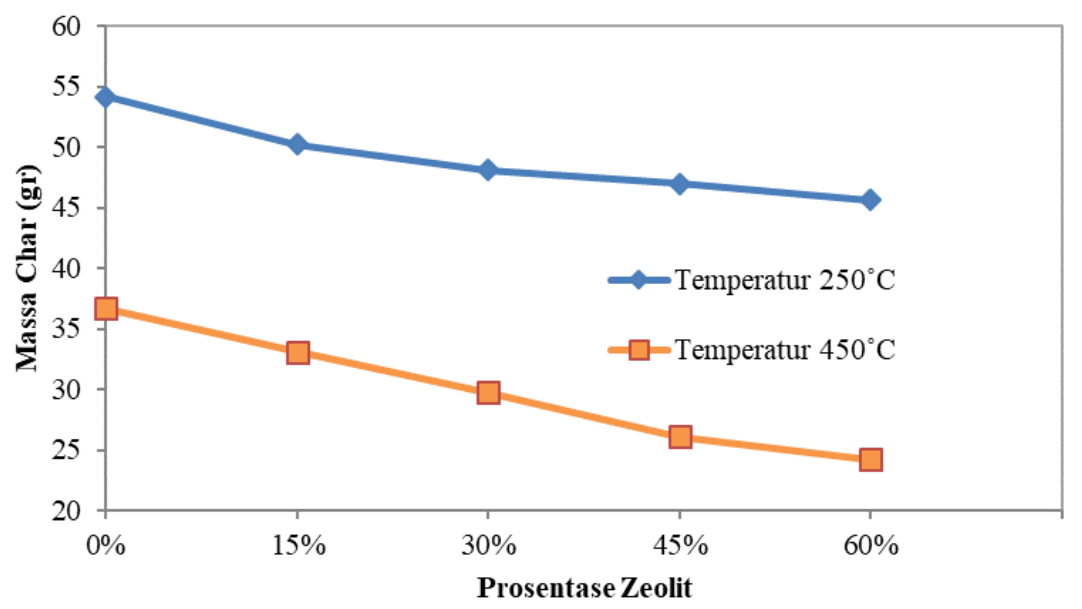

Gambar 4 : Grafik hubungan antara prosentase zeolit dan massa char

Penurunan massa char terjadi karena ketika biomassa dipanaskan, maka biomassa akan terdegradasi atau terdekomposisi secara termal. Semakin besar prosentase zeolit yang digunakan saat proses pirolisis, maka produk massa char yang didapatkan juga semakin kecil. Hal ini dikarenakan semakin besar prosentase katalis zeolit yang digunakan, maka semakin banyak biomassa yang terdekomposisi. Sama dengan proses penurunan volume pirolisis, zeolit disini berfungsi sebagai media perambat panas yang cepat karena kandungan alumina yang dimiliki oleh zeolit, sehingga zeolit berfungsi sebagai media perantara panas dari bed rotary kiln ke biomassa. Hal ini menyebabkan biomassa lebih cepat terdekomposisi, sehingga produk char yang dihasilkan akan menjadi semakin turun. Penggunaan temperatur juga berpengaruh terhadap dekomposisi termal biomassa. Semakin tinggi temperatur pirolisis yang digunakan, semakin banyak biomassa yang terdekomposisi sehingga produk akhir char akan menurun. Temperatur pirolisis menyebabkan pelepasan gas dalam biomassa sehingga hal ini menyebabkan biomassa kehilangan massanya.

Pada $\mathrm{T}=250^{\circ} \mathrm{C}$, evaporasi uap air terjadi pada proses pirolisis dan sebagian komponen penyusun biomassa yang berupa selulosa dan hemiselulosa mulai terdegradasi. Perlakuan yang berbeda untuk $\mathrm{T}=450^{\circ} \mathrm{C}$. Selain terjadi proses evaporasi air, penyusun biomassa yang berupa celllulose dan hemiselulosa terdekomposisi seluruhnya dan sebagian unsur penyusun biomassa yang berupa lignin mulai terdekomposisi sehingga pada penilitian ini penurunan masa biomasa pada $\mathrm{T}=450^{\circ} \mathrm{C}$ akan lebih banyak dibandingkan dengan $\mathrm{T}=250^{\circ} \mathrm{C}$. Hal ini juga terjadi karena selulosa terdekomposisi pada temperatur $240-350^{\circ} \mathrm{C}$, sedangkan hemiselulosa terdekomposisi pada temperatur $200-260^{\circ} \mathrm{C}$. Selain itu, adanya kandungan lain yakni lignin yang terdekomposisi pada temperatur $280-500^{\circ} \mathrm{C}$ [12]. Oleh karena itu, hasil penelitian ini menyatakan bahwa semakin tinggi temperatur pirolisis, maka proses penguapan air terjadi lebih besar yang mengakibatkan volume dan massa char semakin kecil. Hal ini diakibatkan oleh kemampuan zeolit dalam mengikat air baik di dalam biomasa maupun di hasil produk pirolisis yang lain (gas).

\subsection{Pengaruh Prosentase Zeolit terhadap Volume Tar pada Temperatur $250^{\circ} \mathrm{C}$ Dan $450^{\circ} \mathrm{C}$}

Selain mengamati produk char, proses penelitian ini juga mengamati tar. Hasil produk berupa tar dapat dilihat pada gambar 5 dan gambar 6. Pada gambar 5, ditunjukkan grafik hubungan antar variasi prosentase zeolit dan temperatur terhadap volume $\operatorname{tar}$ dengan massa biomassa 150 gram. Pada grafik tersebut terlihat bahwa semakin besar prosentase zeolit dan temperatur saat proses pirolisis berlangsung, maka semakin banyak produk tar akhir yang terbentuk. Hal ini terjadi karena semakin besar temperatur yang digunakan pada saat pirolisis berlangsung, maka semakin banyak biomassa yang ikatan molekulnya terputus sehingga semakin besar pula produk tar dan gas pirolisis [13]. Volume tar terbanyak adalah pada saat perlakuan temperatur pirolisis $450^{\circ} \mathrm{C}$ pada prosentase zeolit $60 \%$ yaitu sebanyak $66 \mathrm{ml}$. Sedangkan volume tar yang dihasilkan tanpa katalis pada temperatur tersebut (prosentase zeolit $0 \%$ ) adalah $46 \mathrm{ml}$. Tetapi, pada temperatur $250^{\circ} \mathrm{C}$ dengan kadar katalis zeolit $60 \%$, produk hasil tar akhir hanya sebanyak 30,5 ml. Sedangkan volume tar tanpa katalis pada temperatur ini adalah $16 \mathrm{ml}$. Dalam hal ini, efek temperatur sebesar $450^{\circ} \mathrm{C}$ akan menghasilkan volume tar yang lebih banyak dibandingkan dengan temperatur $250^{\circ} \mathrm{C}$. Hal ini disebabkan karena pada temperatur $450^{\circ} \mathrm{C}$ seluruh selulosa dan hemiselulosa sudah terdekomposisi, tetapi sebagian lignin masih belum terdekomposisi. Hal ini berbeda dengan temperatur $250^{\circ} \mathrm{C}$ yang hanya sebagian selulosa dan hemiselulosa yang terdekomposisi 
[14]. Selain itu, semakin besar prosentase zeolit yang digunakan, maka produk akhir tar yang dihasilkan juga semakin banyak. Hal ini dikarenakan semakin besar prosentase zeolit yang digunakan maka semakin banyak pula biomassa yang dapat terdekomposisi menjadi tar. Zeolit memiliki struktur permukaan pori yang luas, sehingga permukaan zeolit dapat memilah gas hasil dekomposisi biomassa dengan baik dan akan memecah ikatan hidrokarbon berantai panjang menjadi ikatan hidrokabron berantai pendek dan mudah dikondensasi menjadi minyak pirolisis atau tar [15].

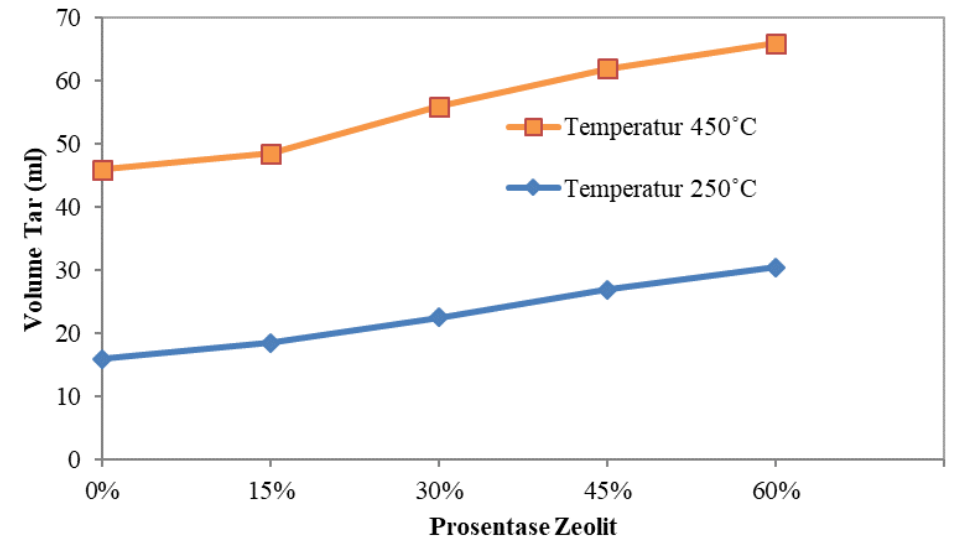

Gambar 5 : Grafik hubungan antara prosentase zeolit terhadap volume tar

Selain itu, zeolit juga berfungsi sebagai penukar kation dengan gas hasil dekomposisi biomassa dimana penukaran kation antara zeolit dan gas tersebut terjadi di permukaan zeolit. Dalam hal ini katalis zeolit bermuatan positif dikarenakan ikatan Browstood sedangkan gas hasil dekomposisi biomassa bermuatan negatif. Akibat perbedaan muatan inilah maka permukaan zeolit akan menarik gas hasil dekomposisi biomassa menuju permukaan pori zeolit sehingga gas tersebut kelebihan muatan positif dan menjadi tidak stabil. Karena ketidakstabilan inilah maka ikatannya menjadi putus dan ikatan hidrokarbonnya menjadi ikatan yang lebih sederhana sehingga mudah dikondensasikan.

\subsection{Pengaruh Prosentase Zeolit terhadap Massa Tar pada Temperatur $250^{\circ} \mathrm{C}$ Dan $450^{\circ} \mathrm{C}$}

Gambar 6 menunjukkan grafik hubungan antara variasi prosentase zeolit dan temperatur terhadap massa tar yang menunjukkan kecenderungan yang sama dengan grafik 5. Pada grafik tersebut terlihat bahwa temperatur pirolisis $450^{\circ} \mathrm{C}$ menghasilkan massa tar yang lebih banyak bila dibandingkan temperatur pirolisis $250^{\circ} \mathrm{C}$. Begitu pula bila pada penelitian ini diberikan prosentase zeolit yang besar, maka produk akhir tar yang didapatkan juga semakin besar. Pada temperatur $450^{\circ} \mathrm{C}$, massa tar yang dihasilkan pada prosentase zeolit $60 \%$ adalah sebanyak 61,65 gram sedangkan yang tanpa katalis zeolit (zeolit 0\%) sebesar 44,36. Pada temperatur pirolisis $250^{\circ} \mathrm{C}$, massa tar yang dihasilkan pada prosentase zeolit $60 \%$ adalah sebesar 29,23 gram, tetapi bila tanpa katalis zeolit, masa tar yang dihasilkan hanya sebesar 15,75 gram.

Dalam hal ini massa dan volume merupakan parameter yang erat hubungannya, yaitu jika terjadi kenaikan volume, maka secara otomatis juga diikuti dengan kenaikan massa, sehingga dalam hal ini semakin besar volume produk tar yang dihasilkan, maka massa yang dihasilkan juga semakin besar, kecuali pada kondisi temperatur tinggi seperti yang diteliti oleh [16].

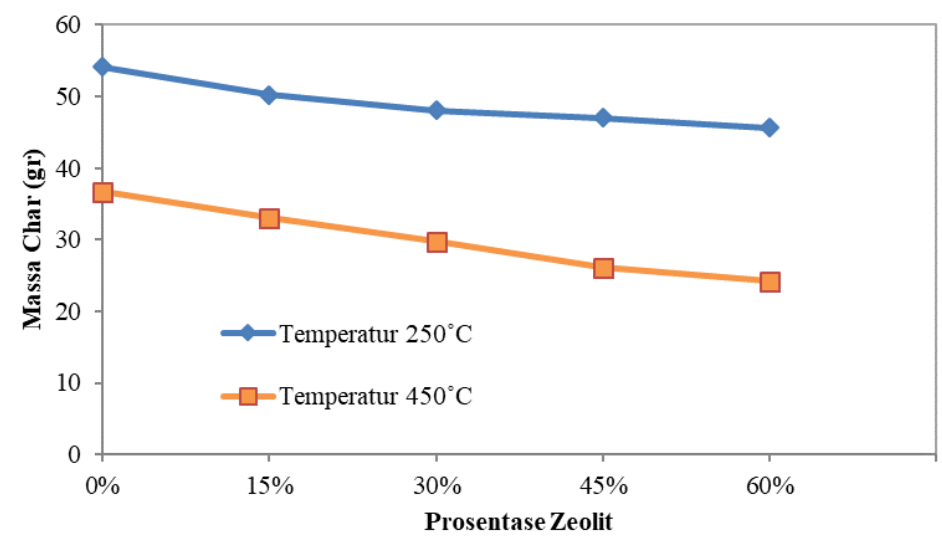


Gambar 6 : Grafik hubungan antara prosentase zeolit terhadap massa tar

Hasil penelitian menunjukkan bahwa zeolit mampu meningkatkan produksi tar dan meningkatkan reduksi charnya sebagai akibat dari reaksi Bronsted-Lowry dan Lewis pada proses pemecahan oleh katalis (catalytic cracking) zeolit, dimana katalis zeolit bermuatan positif dikarenakan adanya ikatan Browstood. Efek dari zeolit ini akan meningkatkan volume dan masa tar yang mempunyai rantai $\mathrm{C}$ lebih pendek dan menurunkan volume dan masa $\mathrm{C}$ pada char akibat dari penarikan $\mathrm{H}+$ yang mengikat senyawa $\mathrm{C}_{\mathrm{x}} \mathrm{H}_{\mathrm{y}} \mathrm{O}_{\mathrm{z}}$ lain di dalam biomassa. Selain itu, efek temperatur pirolisis juga akan membantu zeolit dalam pemecahan biomassa. Semakin tinggi temperatur, maka semakin besar energi panas yang dihasilkan sehingga pemecahan senyawa biomasa dengan rantai $\mathrm{C}$ kompleks (selulosa, hemiselulosa, dan lignin) akan semakin mudah diuraikan menja di senyawa $C$ yang lebih sederhana (pendek). Efek penggunaan rotary kiln pada furnace pirolisis juga mempengaruhi efektifitas transfer masa dan panas pada dekomposisi termal biomasa. Bila dibandingkan dengan penelitian sebelumnya [16], maka fraksi masa produk pirolisis tar jauh lebih besar dibandingkan dengan penelitian sebelumnya. Begitu pula dengan reduksi char yang mempunyai kemampuan mereduksi lebih besar. Hal ini disebabkan adanya perpindahan panas konveksi dan radiasi yang lebih dominan dibandingkan dengan perpindahan panas konduksi yang biasanya mendominasi pada pirolisis fixed bed.

\section{KESIMPULAN}

Penelitian tentang efek penggunaan zeolit pada piroliser jenis rotary kiln memberikan kesimpulan sebagai berikut :

1. Penggunaan zeolit akan memberikan efek catalytic cracking, yaitu dengan adanya peningkatan hasil produksi pirolisis ; volume dan masa tar serta reduksi volume dan masa char. Peningkatan hasil produksi tar dikarenakan terjadi penukaran kation antara zeolit dan gas yang terjadi di permukaan zeolit akibat putusnya ikatan biomasa dan ikatan hidrokarbon biomasa tersebut menjadi ikatan yang lebih sederhana sehingga mudah untuk dikondensasikan. Sebaliknya, reduksi masa char diakibatkan oleh proses penguapan air yang terjadi lebih besar akibat kemampuan zeolit dalam mengikat air yang secara otomatis dapat memproduksi volume dan massa char yang semakin kecil.

2. Efek penggunaan temperatur pirolisis menyebabkan adanya thermal cracking pada variasi temperatur yang berbeda. Semakin tinggi temperatur yang digunakan, maka biomassa akan lebih banyak terdekomposisi baik pada proses pirolisis dengan zeolit maupun tanpa zeolit. Dengan naiknya temperatur, produksi tar dapat meningkat tetapi produksi char menjadi turun. Hal ini juga diakibatkan oleh temperatur yang tinggi dan penggunaan rotary kiln akan berpengaruh pada efektifitas transfer masa dan panas pada dekomposisi termal biomasa.

\section{PERNYATAAN TERIMAKASIH}

Penulis mengucapkan terimakasih yang sebesar-besarnya kepada Mohammad Zainullah atas bantuan dan kerjasamanya dalam pengambilan data di penelitian ini sehingga penelitian ini dapat terselesaikan dengan baik.

\section{DAFTAR PUSTAKA}

[1] RICKY INDRA KUSUMA, et. al, "Natural zeolite from Pacitan Indonesia, as catalyst support for transesterification of palm oil”, Applied Clay Science, v. 74, pp 121-126, April 2013.

[2] THEODORE DICKERSON and JUAN SORIA, "Catalytic Fast Pyrolysis: A Review”, Energies, v. 6 (1), pp 514-538, 2013

[3] DC KUMARA, W WIJAYANTI, D WIDHIYANURIYAWAN, "Pengaruh Penggunaan Katalis (Zeolit) Terhadap Kinetic Rate Tar Hasil Pirolisis Serbuk Kayu Mahoni (Switenia Macrophylla)”, Rekayasa Mesin, v. 6 (1), pp 19-25, 2015

[4] F MAJEDI, W WIJAYANTI, N HAMIDI, "Perubahan Massa dan Nilai Kalor Char dengan Variasi heating Rate dan Suhu pada Pirolisis Serbuk Kayu Mahoni (Switenia Macrophylla)”, Rotor, v. 9(2), pp 5964, 2016

[5] W WIJAYANTI, "Identifikasi Efek Heating Rate terhadap Laju Kinetika Reaksi Pirolisis Kayu Mahoni dengan Thermal Analysis dan Termogravimetry", Rekayasa Mesin, v. 10 (1), pp 65-76

[6] R INDRIYANTO, W WIJAYANTI, L YULIATI, "Simulasi Numerik Distribusi Temperatur Pada Pirolisis Serbuk Kayu Di Fix Bed Pyrolyser", In : Prosiding SENIATI. v. 5 (1), pp 331-335, 2019

[7] W WIJAYANTI, "Identifikasi Komposisi Kimia Tar Kayu Mahoni untuk Biofuel pada Berbagai Temperatur Pirolisis”, Rekayasa Mesin, v. 9 (3), pp. 183-190, 2019 
[8] W WIJAYANTI, MN SASONGKO, “A Great Achievement of Calculated and Experimental Results of Char Kinetic Rate in Woody Mahogany Pyrolysis", MATEC Web of Conferences v. 159 (2040) ,2019

[9] W WIJAYANTI, MN SASONGKO, SASMOKO, “A thermolysis of macroalgae gracilaria affected by temperature pyrolysis”, AIP Conference Proceedings v. 2097 (1), 030047, 2019

[10] A.M. GREENSTEIN,S. GRAHAM, “Thermal Properties and Lattice Dynamics of Polycrystalline MFI Zeolite Films", Journal Nanoscale and Microscale Thermophysical Engineering, v. 10 (4), 2006

[11] R SADEGHBEIGI, Fluid catalytic cracking handbook: An expert guide to the practical operation, design, and optimization of FCC units, Elsevier, 2012

[12] PAULAUSKAS, R., et. al., "Investigation of Regularities of Pelletized Biomass Thermal Deformations during Pyrolysis", Thermal Science, v. 22 (1B), pp. 603-612, 2018

[13] P SUWANDONO, W WIJAYANTI, N HAMIDI, "Pengaruh Temperatur Terhadap Entalpi dan Kinetic Rate Gas Pirolisis Kayu Mahoni”, Rekayasa Mesin , v. 6 (1), 61-67, 2015

[14] E SJOSTROM, Wood chemistry: fundamentals and applications, Elsevier, 1993

[15] Y.C. DANARTO, PRASETYO BUDI UTOMO, FERRY SASMITA, "Pirolisis Limbah Serbuk Kayu dengan Katalisator Zeolit”, In : Prosiding Seminar Nasional Teknik Kimia “Kejuangan, ISSN 1693 4393, Yogyakarta, 26 Januari 2010

[16] I QIRAM, D WIDHIYANURIYAWAN, W WIJAYANTI, "Pengaruh Variasi Temperatur Terhadap Massa dan Energi yang Dihasilkan Pirolisis Serbuk Kayu Mahoni (Switenia Macrophylla) Pada Rotary Kiln”, J. Rotor, v. 8 (2), pp. 1-15, 2015 